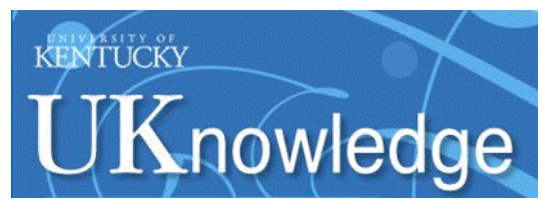

University of Kentucky

UKnowledge

$11-28-2005$

\title{
Intimate Partner Violence and Disabilities among Women Attending Family Practice Clinics
}

Ann L. Coker

University of Texas Health Science Center at Houston, ann.coker@uky.edu

Paige H. Smith

University of North Carolina at Greensboro, phsmith@uncg.edu

Mary Kay Fadden

University of Texas at Brownsville, mary.k.fadden@utb.edu

Follow this and additional works at: https://uknowledge.uky.edu/crvaw_facpub

Part of the Public Health Commons, Social Work Commons, and the Sociology Commons

Right click to open a feedback form in a new tab to let us know how this document benefits you.

\section{Repository Citation}

Coker, Ann L.; Smith, Paige H.; and Fadden, Mary Kay, "Intimate Partner Violence and Disabilities among Women Attending Family Practice Clinics" (2005). CRVAW Faculty Journal Articles. 112.

https://uknowledge.uky.edu/crvaw_facpub/112

This Article is brought to you for free and open access by the Center for Research on Violence Against Women at UKnowledge. It has been accepted for inclusion in CRVAW Faculty Journal Articles by an authorized administrator of UKnowledge. For more information, please contact UKnowledge@lsv.uky.edu. 


\section{Intimate Partner Violence and Disabilities among Women Attending Family Practice Clinics}

\section{Digital Object Identifier (DOI)}

http://dx.doi.org/10.1089/jwh.2005.14.829

\section{Notes/Citation Information}

Published in Journal of Women's Health, v. 14, no. 9, p. 829-838.

This is a copy of an article published in the Journal of Women's Health (c 2005 Mary Ann Liebert, Inc.; Journal of Women's Health is available online at: http://online.liebertpub.com/loi/jwh

Dr. Ann Coker had not been a faculty member of the University of Kentucky at the time of publication. 


\title{
Intimate Partner Violence and Disabilities among Women Attending Family Practice Clinics
}

\author{
ANN L. COKER, Ph.D., ${ }^{1}$ PAIGE H. SMITH, Ph.D., ${ }^{2}$ and MARY K. FADDEN, M.P.H. ${ }^{3}$
}

\begin{abstract}
Purpose: To estimate the frequency and type of disabilities preventing work among those experiencing intimate partner violence (IPV) compared with those never experiencing IPV.

Methods: We used a large cross-sectional survey of women, ages 18-65, attending family practice clinics from 1997 through 1998. Participation included a 5-10-minute in-clinic survey assessing IPV experience and a longer telephone survey assessing health status and chronic disabilities that prevented work outside the home or housework.

Results: Of 1,152 eligible women surveyed, $54 \%$ experienced some type of IPV, and $24 \%$ were currently in a violent relationship. Women who had ever experienced IPV were more than twice as likely to report a disability (adjusted odds ratio [aOR] $=2.2,95 \%$ confidence interval $[\mathrm{CI}] 1.6,3.0)$. The most commonly reported disabilities were those associated with heart or circulatory disease $(4.9 \%)$, followed by back problems $(3.5 \%)$, chronic pain $(3.4 \%)$, arthritis $(3.0 \%)$, nerve system damage $(2.4 \%)$, asthma or another respiratory problem including emphysema $(1.7 \%)$, and either depression $(1.6 \%)$ or another mental illness $(1.0 \%)$. Women ever experiencing IPV were more likely to report a disability due to generalized chronic pain $(\mathrm{aOR}=2.5,95 \%$ CI 1.5, 4.3) and mental illness (aOR $=4.5,95 \%$ CI 1.5, 13.1). IPV-related injuries were associated in a dose-dependent manner with having any disability and with disability from chronic pain, asthma and other respiratory diseases, mental illness, and chronic diseases.

Conclusions: Primary care-based efforts to screen for IPV and effectively intervene to reduce the impact of IPV on women's lives must be a public health priority to reduce the shortterm and long-term health effects, including disabilities.
\end{abstract}

\section{INTRODUCTION}

$\mathbf{I}_{\mathrm{p}}^{\mathrm{N}}$ NTIMATE PARTNER VIOLENCE (IPV) is a significant public health problem that has both short-term and long-term physical and mental health consequences for women and their families. ${ }^{1}$ Preva- lence estimates for current IPV among women receiving care in primary healthcare settings range between $7 \%$ and $29 \% .^{2-7}$ Women experiencing IPV use a disproportionate share of healthcare services, making more visits to emergency departments, primary care facilities, and mental

\footnotetext{
${ }^{1}$ Division of Epidemiology, University of Texas Health Science Center, School of Public Health, Houston, Texas.

${ }^{2}$ Center for Women's Health and Wellness, University of North Carolina at Greensboro; Greensboro, North Carolina.

${ }^{3}$ University of Texas-Houston School of Public Health at Brownsville, Brownsville, Texas.

This work was funded by R49 of the CDC National Center for Injury Prevention and Control and the Disabilities Prevention Program of the National Center for Environmental Health.
} 
health agencies than nonabused women, ${ }^{8-14}$ yet little research has explored potential associations with IPV and disabilities. ${ }^{14-18}$

Victims of physical IPV may be at increased risk of traumatic head injuries, ${ }^{19-22}$ resulting in cognitive deficits ${ }^{19}$ and traumatic brain injuries in a dose-dependent manner. ${ }^{23}$ Strangulation is commonly reported by IPV victims, ${ }^{24,25}$ and neurological symptoms have been reported. ${ }^{24,26}$ Case studies suggest that strangulation may be associated with stroke and chronic headaches. ${ }^{27,28}$ In a cross-sectional study of 860 women selected from a national sexuality survey (half physically disabled), $62 \%$ of both the disabled and not disabled had experienced physical or sexual abuse, most at the hands of an intimate partner. Disabled women endured the abuse for longer time periods than nondisabled women. ${ }^{29}$

Several studies report that IPV is associated with generalized and chronic pain, $, 14,30,31$ although others do not find this association. ${ }^{17,32,33}$ Studies of patients with specific pain-related disorders find that women experiencing partner violence are more likely than other patients to have chronic pelvic pain, ${ }^{31,32,34}$ fibromyalgia, ${ }^{35}$ gastrointestinal disorders, ${ }^{36}$ and to be chronic pain clinic patients. 37,38

The purpose of this analysis is to explore the association between IPV by type (physical, sexual, and psychological), timing (current or past), and disabilities preventing work as reported in a clinical population of women attending primary health clinics. We hypothesize that the chronic nature of repeated physical assaults, measured as IPV-related injuries, would be associated with disabilities characterized as generalized chronic pain (e.g., chronic pain, abdominal pain, back problems, or arthritis) or nervous system injuries or disorders (e.g., nerve damage, numbness, migraines, epilepsy, or seizures), given the impact of persistent blunt trauma on muscle tissue and nerves. Because past research ${ }^{1,39,40}$ has indicated that both physical abuse and psychological abuse were associated with both chronic disesase and poorer mental health (e.g., depression and anxiety), we hypothesized that both physical and psychological IPV would be associated with reporting disabilities due to chronic disease or mental illness.

This work adds to the limited literature addressing IPV and disabilities. Because the study is large, we have data to characterize physical, sexual, and psychological abuse using scores in- dicating frequency or severity of IPV, and we can explore potentially different mechanisms for the impact of IPV by type on specific disabilities. To further address mechanisms, we grouped disabilites to investigate consequences of repeated physical assaults (disabilities from chronic pain or nervous or muscular system disorders) or those more associated with psychological abuse (disabilites from chronic depression or other mental illness).

\section{MATERIALS AND METHODS}

\section{Data collection}

A detailed description of the study methods has been published elsewhere. ${ }^{5,14,41}$ Briefly, in this cross-sectional study, trained recruiters approached and interviewed 1152 women seeking medical care in two university-associated family practice clinics from February 1997 through January 1999. Eligible subjects were women, ages 18-65, who were insured either by Medicaid or a managed care provider. Because we focused on IPV, including sexual violence in intimate relationships, study inclusion required an intimate relationship with a man for at least 3 months. Study participation included a 5-10-minute inclinic interview to screen for IPV and a 30-45minute telephone interview to assess the woman's medical history and current health status. We used computer-assisted interviewing for both in-clinic and telephone interviews to reduce errors and rapidly provide scale scores for IPV measures. Women were reimbursed for their time in completing these interviews. Women currently in abusive relationships were counseled by recruiters and referred to local services for victims. For safety reasons, women currently in violent relationships were given the option to complete this longer interview in the clinic. The University of South Carolina Institutional Review Board approved this project; all women signed consent forms.

Our refusal rate was $10.2 \%$; there were no differences between refusers and willing participants by race, age, or insurance type.

\section{Measures of IPV}

IPV was characterized by (1) the timing of the violence (in a past vs. a current or most recent intimate relationship), (2) the type of violence 
(physical asssault, sexual asssault, or psychological battering/emotional abuse) and (3) the frequency of IPV. Women were first asked about their current male partner. If a woman was not currently in a relationship, we asked her to think about her most recent relationship. We then asked about demographic characteristics of the current or most recent partner and about her IPV experience in this relationship.

We used information regarding current and past intimate relationships to characterize IPV experience by type. Note that the tools used to define IPV types differ by timing. We categorized lifetime IPV based on the following hierarchical categories. Physical or sexual IPV included women who had ever experienced physical or sexual IPV in any past relationship (based on the modified Abuse Assessment Scale [AAS] ${ }^{42}$ ) or in her current or most recent relationship (based on the modified Index of Spouse Abuse-Physical $\left.[\mathrm{ISA}-\mathrm{P}]^{43}\right)$. Psychological IPV alone included women who reported emotional abuse in any past relationship or scored as battered on the Women's Experience with Battering Scale (WEB $)^{44,45}$ but not as experiencing physical IPV (based on the ISA-P) by a current or most recent partner. We also categorized current IPV by type (sexual, physical, and psychological battering IPV).

\section{Current IPV}

To assess the frequency of current physical and sexual IPV, we used a modified ${ }^{41} 15$-item version of the ISA-P ${ }^{43}$ (Cronbach's $\alpha$ for 15-item scale $=$ 0.91). For each item in the questionnaire, the women responded on a scale from 1 (never) to 7 (all of the time). A total score for the ISA-P ranges from 0 to $100 \%$; an ISA-P cutpoint of $>3$ defined current physical IPV (IPV-P) in this study (based on earlier validation of the ISA-P by Attala et al. $\left.{ }^{46}\right)$. We used 3 items of the 15-item ISA-P to assess sexual violence. The same response ranges were used, and the same weighted scale score and cutpoints were used to define sexual IPV.

We used the WEB Scale as a measure of battering. Women who scored positive on the WEB Scale but did not experience physical or sexual IPV as measured by the ISA-P were considered to be psychologically battered. As reported elsewhere, ${ }^{41,45,47}$ the WEB Scale has good construct validity, accurately discriminates battered from nonbattered women, and shows strong internal consistency (Cronbach's $\alpha=0.95$ in this sample). Each item is scored in a Likert format ranging from "agree strongly" to "disagree strongly." Scores on this scale range from 10 to 60; a cutpoint of $>20$ was used to distinguish those experiencing this type of IPV.

\section{Past IPV}

We measured any past IPV-P using a modification of McFarlane's Abuse Assessment Scale. ${ }^{42}$ Our modification was to frame questions to ask specifically about physical, sexual, and emotional violence by an intimate male partner. ${ }^{45}$ We asked about each type of violence separately and followed up with a question assessing frequency of violence for those reporting IPV. We prefaced these questions about IPV in a past relationship by asking women to think about past intimate relationships with men (lasting at least 3 months) that occurred before the relationship they were just questioned about (the current or most recent relationship). Women responding affirmatively to any of these individual questions were categorized as experiencing past IPV by respective type, independent of the frequency of violence experienced.

\section{Measures of IPV frequency}

To allow a more appropriate comparison among ordinal measures of injury, physical violence, sexual violence, and battering scale scores and the odds of disability, we created summed frequency measures of IPV within IPV type. The two frequency measures of sexual violence (range 0-17) and physical violence (range $0-15$ ) are based on both current (ISA-P) and past partner violence (AAS frequency measures) summed. The response options for the ISA-P (current IPV) were comparable to the frequency response options from the AAS (past IPV). IPV-associated injuries (range 0-5) are those reported for IPV experienced at any point during the woman's lifetime and are measures of both injury frequency and severity. We do not have a frequency measure of past emotional abuse; thus, the dichotomous variable was used. Finally, the WEB Scale was transformed from the original score ranging from 10 to 60 by dividing by 10 ; the range for these transformed scores was $0-6$. The WEB Scale score measures current/recent battering independent of the ISA score.

\section{Demographic correlates of IPV}

In the in-clinic questionnaire, we collected the following demographic characteristics for the 
women: current marital status, age, race/ethnicity, education, and health insurance type.

\section{Disability categorizations}

We used a modification of the National Health Interview Survey ${ }^{48}$ to ascertain whether women have ever been told they had a range of mental and physical health conditions. We also asked if they had ever had a chronic disability that prevented them from working outside the home or from doing housework if they were a homemaker. Women used their own words to describe the condition that led to the disability. From their description, disabilities were grouped in the following ways (Table 1): generalized chronic pain (included joint injuries, joint pain, joint or limb replacement, broken bones, and carpal tunnel syndrome; four specific categories with sufficient number for separate analyses within the generalized chronic pain category were chronic pain, abdominal pain, back problems, and arthritis); disabilites associated with the nervous system (included two specific categories of nerve damage, and chronic numbness and fibromyaglia and neuropathy); disabilities associated with brain or head trauma (epilepsy or seizures and migraine headaches), asthma or respiratory conditions (included as two specific categories of asthma or emphysema and sarcodoisis, chronic pulmonary disease, and the generic respiratory problems included under the respiratory problem disability heading), mental illnesses (two categories: depression and other mental illnesses, including schizophrenia, bipolar disorder, having hallucinations, panic attacks, and the generic mental health problems); chronic disease disabilities (including heart or circulatory disease, including hypertension, coronary heart disease or myocardial infarction, or hypercholesterolemia), stroke, thrombosis, diabetes, cancer, chronic kidney or bladder infection or diseases); blindness or glaucoma; and autoimmune diseases (included as three specific categories: allergies, multiple sclerosis, and systemic lupus erythematosus). We excluded disabilities caused by temporary conditions (pregnancy, $n=2$ ) and those in which women gave no description of the disability $(n=$ 78).

\section{Statistical analyses}

We calculated the prevalence of disability by type of disability (Table 1). We assessed whether women who reported a disability thought that an injury caused the disability and, further, whether that injury was due to IPV. With this analysis, we estimated the proportion of the disability women perceived as attributable to IPV. Because increasing age was strongly associated with having a disability, all analyses were adjusted for age as a continuous variable in multiple logistic regression models. To address the association between IPV and disability, we used a series of logistic regression analyses. Any disability and the specific disability grouping were included in separate models as dependent variables. Because we do not know the timing of the onset of the disability, we explored the association between having a disability and timing of IPV (past or current). Two dummy variables were created to compare those who never experienced IPV in any relationship (referent group) with those who experienced any type of IPV in a (1) current or most recent relationship and (2) past relationship only. With this analysis, we are attempting to address current vs. cumulative effects of the IPV on disability. Finally, we explored the association between frequency of IPV by type and disabilities (Table 3). All analyses were conducted using PC-SAS.

\section{RESULTS}

Table 1 presents the prevalence of disabilities reported by women in the sample. These include disabilities preventing working outside the home or doing housework if the woman was a homemaker. Women could report multiple conditions leading to disability status; therefore, the numbers reported do not sum to 221, the total number of women reporting a disability $(19.2 \%$ of the sample). The most commonly reported disabilities were those associated with heart or circulatory disease $(4.9 \%)$, followed by back problems $(3.5 \%)$, chronic pain $(3.4 \%)$, arthritis $(3.0 \%)$, nerve system damage $(2.4 \%)$, asthma or another respiratory problem including emphysema $(1.7 \%)$, and either depression $(1.6 \%)$ or another mental illness $(1.0 \%)$.

Those reporting a disability were older than those who did not; the mean age \pm standard deviation (SD) of those without a disability was $36.4 \pm 10.5$, whereas among those with a disability, the mean age \pm SD was $44.3 \pm 11.1$. All subsequent associations were age adjusted. Because having a disability makes one eligible for Medicaid, we found, as anticipated, that being currently 
Table 1. Prevalence of Ever Having a Disability Preventing Work by Type Among 1152 Eligible Women Surveyed

\begin{tabular}{|c|c|c|}
\hline Disability categories & $\mathrm{n}$ & $\%$ \\
\hline Any disability preventing work or housework (if homemaker) & 221 & 19.2 \\
\hline Generalized chronic pain ${ }^{\mathrm{a}}$ & 81 & 7.0 \\
\hline Chronic pain & 39 & 3.4 \\
\hline Abdominal pain & 10 & 0.9 \\
\hline Back problem & 40 & 3.5 \\
\hline Arthritis & 35 & 3.0 \\
\hline Disabilities associated with neural or muscular trauma ${ }^{b}$ & 28 & 2.4 \\
\hline Nerve damage or numbness & 14 & 1.2 \\
\hline Disabilities associaated with brain or head trauma & 14 & 1.2 \\
\hline Epilepsy or seizures & 2 & 0.2 \\
\hline Migraines & 12 & 1.0 \\
\hline Asthma or other respiratory problems ${ }^{\mathrm{C}}$ & 20 & 1.7 \\
\hline Asthma & 15 & 1.3 \\
\hline Emphysema & 6 & 0.5 \\
\hline Mental illness & 30 & 2.6 \\
\hline Depression & 18 & 1.6 \\
\hline Other mental illness (schizophrenia, bipolar disorder) ${ }^{\mathrm{d}}$ & 12 & 1.0 \\
\hline Chronic disease disabilities & 73 & 6.3 \\
\hline $\begin{array}{l}\text { Heart or circulatory disease (includes hypertension, } \\
\text { coronary heart disease, and hypercholesterolemia) }\end{array}$ & 56 & 4.9 \\
\hline Stroke & 3 & 0.3 \\
\hline Thrombosis & 6 & 0.5 \\
\hline Diabetes & 17 & 1.5 \\
\hline Cancer & 10 & 0.9 \\
\hline Chronic kidney or bladder infections or diseases & 8 & 0.7 \\
\hline Blindness or glaucoma & 7 & 0.6 \\
\hline \multicolumn{3}{|l|}{ Autoimmune diseases } \\
\hline Allergies & 9 & 0.8 \\
\hline Multiple sclerosis & 4 & 0.3 \\
\hline Lupus & 6 & 0.5 \\
\hline
\end{tabular}

ancluded joint injuries, joint pain, joint or limb replacement, broken bones, and carpal tunnel syndrome and the four subgroups with sufficient number for separate analyses (chronic pain, abdominal pain, back problems, and arthritis).

bIncluded nerve damage, numbness, neuropathy, and fibromyalgia.

'Included sarcoidosis, chronic pulmonary disease, generic respiratory problems, and subcategories of asthma and emphysema.

dIncluded schizophrenia, bipolar disorder, having hallucinations, panic attacks, and the generic mental health problems.

on Medicaid was strongly associated with having a disability. Those with a disability had less education and were less likely to report being currently married. Those with a disability were also more likely to report that they thought their current or most recent partner had a problem with drugs or alcohol, and were more likely to report having ever smoked cigarettes than women not reporting a disability. Based on this demographic profile, subsequent logistic regression analyses include age, education, and cigarette smoking as confounders.

Women ever experiencing IPV were more likely than those never experiencing IPV to report that an injury caused the disability; $41.8 \%$ of women experiencing IPV reported that an injury caused the disability compared with $23.5 \%$ of women never experiencing IPV $(p=0.001)$. Among those experiencing IPV, the proportion reporting that the injury was a result of IPV was greater for those with more chronic conditions or disease disabilities (55\%) than for disabilities associated with such injuries as chronic pain or nerve system damage (21\%).

Recognizing that many women experience IPV in more than one intimate relationship and that we do not know when the disability first occurred, we assessed the association between having a disability in a current and past relationships. An association between disabilites and current IPV would suggest that women with a disability might be at greater risk or perhaps be more vul- 
nerable to violence by a partner. An association between disabilities and past IPV more strongly suggests that the disability was a consequence of the IPV. Having a disability was associated with current and past IPV; the association was stronger for those experiencing current IPV (Table 2). A similar pattern was noted for depression or other mental illness and nervous system injuries or disorders resulting in a disability. The adjusted odds ratios (aOR) were of similar size for past and current IPV and having a disability from generalized chronic pain. Having a disability resulting from blindness or glaucoma, nervous or muscular disorders, and chronic diseases was associated with only those currently experiencing IPV. IPV was not signficantly associated with having a disability resulting from epilepsy, migraines, seizures, asthma, or an autoimmune disorder.

Finally, we examined the associations between frequency of IPV by type and category of disability in an attempt to evaluate a dose-response association (Table 3). Sexual IPV was associated with having any type of disability in a dose-dependent manner, yet not with any specific disability. The frequency of having an IPV-associated injury was associated in a dose-dependent manner with having any disability and with chronic pain, asthma and other respiratory diseases, mental illness, and chronic diseases. Reporting emotional abuse in a past relationship was associated with any disability, chronic pain, and mental illness. Finally, increasing WEB scores, a measure of battering, was associated with having any disability and with mental illness, chronic disease, and blindness or glaucoma in a dose-dependent manner.

\section{DISCUSSION}

To briefly summarize, we found that IPV (all types) was associated with having any disability and, specifically, with disabilities from chronic pain and mental illness. IPV may cause acute and chronic injuries that may directly lead to disability, and IPV can lead to disabilites indirectly through distress and adverse lifestyle or coping strategies. High scores on the WEB Scale were associated with any disability, mental illness, chronic disease, and blindness or glaucoma. The latter finding suggests that the disability may increase the risk of battering. Some IPV-associated disability is the direct result of an injury, but most IPV-associated disability results from women's long-term exposure to chronic abuse. Although this finding may be counterintuitive in that physically abused women do experience injuries that may cause a disability, it is consistent with the growing literature indicating that indirect effects of both physical and psychological IPV may be more important than the direct physical injuries that many abused women experience. ${ }^{1,14,16,17,34,39}$

Table 2. Disability as a Result of Any Injury and as a Result of IPV-Associated Injury

\begin{tabular}{|c|c|c|c|c|c|}
\hline \multirow[b]{3}{*}{ Disability, by category } & \multicolumn{3}{|c|}{$\begin{array}{l}\% \text { with disability by } \\
\text { timing of IPV experienced }\end{array}$} & \multicolumn{2}{|c|}{$\begin{array}{l}a O R^{\mathrm{a}} \text { and } 95 \% \text { CI for IPV } \\
\text { timing and disability type }\end{array}$} \\
\hline & \multirow{2}{*}{$\begin{array}{l}\text { Current IPV } \\
(\mathrm{n}=203)\end{array}$} & \multirow{2}{*}{$\begin{array}{l}\text { Past IPV } \\
(\mathrm{n}=421)\end{array}$} & \multirow{2}{*}{$\begin{array}{c}\text { No IPV } \\
(\mathrm{n}=530)\end{array}$} & & \\
\hline & & & & Current IPV & Past IPV \\
\hline $\begin{array}{l}\text { Any disability preventing work } \\
\text { or housework (if homemaker) }(n=221)\end{array}$ & 32.5 & 20.7 & 12.8 & $3.2(2.2,4.9)$ & $1.9(1.3,2.7)$ \\
\hline \multicolumn{6}{|l|}{ Type of disability } \\
\hline Generalized chronic pain $(n=81)$ & 9.4 & 9.7 & 4.0 & $2.5(1.3,5.0)$ & $2.8(1.6,4.9)$ \\
\hline $\begin{array}{l}\text { Nervous system injuries or disorders } \\
\quad(n=28)\end{array}$ & 3.0 & 1.2 & 0.6 & $5.4(1.2,27.2)$ & $2.2(0.5,9.4)$ \\
\hline $\begin{array}{l}\text { Asthma or other respiratory } \\
\text { problems }(n=20)\end{array}$ & 3.5 & 1.7 & 1.1 & $3.1(0.9,10.6)$ & $1.5(0.5,4.6)$ \\
\hline Epilepsy, seizures, migraines $(n=14)$ & 3.0 & 1.0 & 0.8 & $3.2(0.9,12.2)$ & $1.1(0.3,4.6)$ \\
\hline Mental illness or depression $(n=30)$ & 6.9 & 2.9 & 0.8 & $9.7(3.0,35.5)$ & $3.1(1.0,9.8)$ \\
\hline Chronic diseases $(n=73)$ & 10.8 & 6.4 & 4.5 & $2.5(1.3,4.7)$ & $1.5(0.8,2.8)$ \\
\hline Autoimmune conditions $(n=19)$ & 1.9 & 1.4 & 1.5 & $1.3(0.3,4.9)$ & $1.0(0.4,3.1)$ \\
\hline Blindness or glaucoma $(n=7)$ & 2.0 & 0.5 & 0.2 & $10.6(1.1,251.1)$ & $3.3(0.3,37.0)$ \\
\hline
\end{tabular}

aReferent group for all comparisons is those never experiencing IPV; OR adjusted for age, education, and cigarette smoking. 
Table 3. IPV Experience in Current or Most Recent Relationship and Disability Status

\begin{tabular}{|c|c|c|c|c|c|}
\hline \multirow[b]{2}{*}{ Disability } & \multicolumn{5}{|c|}{$a O R^{\mathrm{a}}(95 \% \mathrm{CI})$ for disability and IPV frequency (by type) } \\
\hline & $\begin{array}{l}\text { Frequency of } \\
\text { sexual IPV } \\
\text { (range 0-17) }\end{array}$ & $\begin{array}{l}\text { Frequency of } \\
\text { physical IPV } \\
\text { (range 0-15) }\end{array}$ & $\begin{array}{l}I P V \text {-associated } \\
\text { injury } \\
\text { (range 0-5) }\end{array}$ & $\begin{array}{c}\text { Past emotional } \\
\text { abuse } \\
\text { (yes vs.no) }\end{array}$ & $\begin{array}{l}W E B^{\mathrm{b}} \text { scale score } \\
\text { (range 0-6) } \\
\text { Current IPV }\end{array}$ \\
\hline $\begin{array}{l}\text { Any disability preventing } \\
\text { work }(n=221)\end{array}$ & $1.10(1.01,1.18)$ & $0.91(0.83,1.00)$ & $1.45(1.25,1.70)$ & $1.51(1.06,2.15)$ & $1.24(1.09,1.41)$ \\
\hline \multicolumn{6}{|l|}{ Type of disability } \\
\hline $\begin{array}{l}\text { Generalized chronic pain } \\
\quad(n=81)\end{array}$ & $1.05(0.95,1.17)$ & $0.94(0.83,1.07)$ & $1.35(1.09,1.67)$ & $2.26(1.34,3.80)$ & $0.93(0$ \\
\hline $\begin{array}{l}\text { Nervous or muscular } \\
\text { injuries or disorders } \\
(n=14)\end{array}$ & 1.01( & 0.72 & 1.27( & 2.45 & 1.28 \\
\hline $\begin{array}{l}\text { Epilepsy, seizures, } \\
\text { migraines }(n=14)\end{array}$ & $1.18(0.99,1.41)$ & $1.07(0.87,1.33)$ & $1.30(0.79,2.13)$ & $1.33(0.36,4.85)$ & $1.13(0.78,1.65)$ \\
\hline $\begin{array}{l}\text { Asthma or other } \\
\text { respiratory problems } \\
(n=20)\end{array}$ & $0.95(0.75,1.20)$ & $1.13(0.92,1.38)$ & $1.51(1.04,2.21)$ & $0.85(0.30,2.44)$ & $1.06(0.77,1.50)$ \\
\hline $\begin{array}{l}\text { Mental illness or } \\
\text { depression }(n=30)\end{array}$ & $1.03(0.87,1.20)$ & $0.86(0.69,1.07)$ & $1.58(1.15,2.18)$ & $3.35(1.42,7.91)$ & $1.57(1.23,1.99)$ \\
\hline Chror & ) & & 1.41 & 1.4 & 1.24 \\
\hline $\begin{array}{l}\text { Autoimmune conditions } \\
\quad(n=19)\end{array}$ & $1.10(0.94,1.48)$ & $1.04(0.77,1.41)$ & $1.35(0.87,2.11)$ & $0.32(0.08,1.20)$ & $1.00(0.65,1.54)$ \\
\hline $\begin{array}{l}\text { Blindness or glaucoma } \\
(n=7)\end{array}$ & $1.12(0.91,1.39)$ & $0.91(0.65,1.28)$ & $1.03(0.49,2.17)$ & $2.00(0.37,10.95)$ & $1.75(1.07,2.86)$ \\
\hline
\end{tabular}

aOR adjusted for age, education, and respondent's current smoking status.

bWEB, Women's Experience with Battering Scale.

Our finding that IPV is more commonly reported by women who have ever had a disability preventing work is consistent with several studies that report that IPV is associated with generalized and chronic pain, $14,30,31$ yet others $^{17,32,33}$ have not found this association. We found that a history of IPV was associated with having disabilities from chronic pain disorders. This finding is consistent with several studies of patients with specific pain-related disorders that found that women experiencing IPV are more likely than other patients to have chronic pelvic pain $^{31,32,34}$ fibromyalgia ${ }^{35}$ and to be chronic pain clinic patients. ${ }^{37,38}$ Our finding that a history of IPV was associated with disorders potentially caused by head trauma or strangulation (migraines, epilepsy, and seizure disorders) is consistent with reports by others noting an increased risk of traumatic brain injury ${ }^{19-22}$ in a dose-dependent manner. ${ }^{23}$ Others report neurological symptoms among women repeatedly strangled by an intimate partner, ${ }^{24,26}$ and strangulation may be associated with stroke and chronic headaches. ${ }^{27,28}$

This research adds to existing literature by addressing the association between IPV by type (sexual, physical, and psychological battering/ emotional abuse) and timing (current and past) and having a disability severe enough to prevent work either permanently or temporarily. This sample is one of the largest studies of IPV and disabilites. Because we included women seeking primary care as the sampling frame, we obtained a sample more reflective of and, therefore, generalizable to the general population vs. studies of women seeking specialty care for pain disorders, gastrointestinal disorders, or mental health clinics.

We also asked women about their experience with IPV in their current or most recent relationship as well as in past relationships. By asking women directly about both their IPV experiences and their history of a disability and the type of disability, we have more complete data to characterize both the exposure and outcomes of interest. Most research to date has focused only on physical IPV while ignoring the impact that sexual IPV and battering/ emotional abuse may have. We also have data to explore whether IPV frequency and injuries are associated with disabilities in a dose-dependent manner. 
This study is not without limitations. We do not have data to reconstruct the correct temporal sequence based on the woman's age at disability. IPV may be a response to the disability, or the disability may be a consequence of IPV. We attempted to address this issue by correlating timing of IPV with disability status. Misclassification of exposure (IPV by type, timing, and frequency) and outcome is a possibility in any study that relies on self-report. However, women are the best source of data on their own IPV experience. Further, as we are interested in a history of disabilities that may have permanently or temporarily prevented work, the woman's recall may again be the best data source. Although medical records document disabilities currently preventing work, they frequently do not document temporary disability status. Because this study was designed to recruit women in managed care or Medicaid populations, we cannot generalize beyond these two groups of insured women or to nonclinical samples. For some specific disabilities, we lack statistical power to provide precise estimates of the associations. We excluded women with mental challenges from the sample because they could not provide informed consent. Thus, we cannot provide estimates of the impact of IPV for mentally challenged women. Finally, we allowed women to define disability for themselves. Women were asked if they had had a disability preventing work or housework. We did not define or provide a check list of disabilities. Similarly, we did not define a time period in which a woman might have experienced a disability precluding work. It is, therefore, possible that those labeled as having a disability include a heterogeneous group with permanent disabilities as well as being temporarily disabled.

Our finding that being on Medicaid was strongly associated with having a disability (56\% of those on Medicaid had a disability compared with $17 \%$ of those insured through an HMO) and that women on Medicaid were significantly more likely to report experiencing an IPV-associated injury $(61.1 \%)$ compared with HMO-insured women $(23.6 \%)$ suggests that IPV could be the reason some women are on Medicaid. Earlier research found that among Medicaid recipients, those reporting scores for current physical abuse had $55 \%$ higher Medicaid costs than did women who experienced no IPV. ${ }^{49}$ Taken together, these data suggest that IPV has significant individual health consequences as well as economic costs to society by increasing the numbers of women receiving federally funded insurance.

We found that several disabilities may be associated with IPV in a dose-dependent manner. In some cases, the violence may be a consequence of the disability and its associated vulnerability, and in other cases, the violence may contribute to the disability. Additional research is needed to better distinguish the cause and effect relationship. However, it is essential that those providing services to women with disabilities be aware that disabilities may increase the risk of current and perhaps future violence. Routine abuse assessments of all women by healthcare providers will identify those potentially at risk for poorer health outcomes and disabilities. Early identification may reduce cumulative and long-term effects of IPV on risk of disabilities. Our finding that women experiencing IPV are more likely to experience disabilities, defined as disabilities preventing the normal activities of work or housework, indicates that these disabilities have an impact on women and their families and, therefore, have economic implications for women, families, and society as a whole.

\section{REFERENCES}

1. Campbell JC. Health consequences of intimate partner violence. Lancet 2002;359:1331.

2. Freund KM, Bak SM, Blackhall L. Identifying domestic violence in primary care practice. J Gen Intern Med 1996;11:44.

3. Gin NE, Rucker L, Frayne S, Cygan R, Hubbell F. Prevalence of domestic violence among patients in three ambulatory care internal medicine clinics. J Gen Intern Med 1991;6:317.

4. Rath GD, Jarratt LG, Leonardson G. Rates of domestic violence against adult women by men partners. J Am Board Fam Pract 1989;2:227.

5. Coker AL, Smith PH, McKeown RE, King MJ. Frequency and correlates of intimate partner violence by type: Physical, sexual, and psychological battering. Am J Public Health 2000;90:553.

6. Bullock L, McFarlane J, Bateman LH, Miller V. The prevalence and characteristics of battered women in a primary care setting. Nurse Pract 1989;14:53.

7. McNutt LA, Carlson BE, Rose IM, Robinson DA. Partner violence intervention in the busy primary care environment. Am J Prev Med 2002;22:84.

8. Plichta S. The effects of woman abuse on health care utilization and health status: A literature review. Womens Health Issues 1992;2:154.

9. Haber JD. Abused women and chronic pain. Am J Nurs 1985;85:1010. 
10. Appleton $W$. The battered woman syndrome. Ann Emerg Med 1980;9:84.

11. Tilden VP, Shepherd P. Increasing the rate of identification of battered women in an emergency department: Use of a nursing protocol. Res Nurs Health 1987;10:209.

12. McLeer SV, Anwar R. A study of battered women presenting in an emergency department. Am J Public Health 1989;79:65.

13. Bergman B, Brismar B. [Victims and perpetratorsAbuse seen from the perspective of emergency care.] Lakartidningen 1992;89:3371, 3375.

14. Coker AL, Smith PH, Bethea L, King MR, McKeown RE. Physical health consequences of physical and psychological intimate partner violence. Arch Fam Med 2000;9:451.

15. Plichta SB, Falik M. Prevalence of violence and its implications for women's health. Womens Health Issues 2001;11:244.

16. Hathaway JE, Mucci LA, Silverman JG, Brooks DR, Mathews R, Pavlos CA. Health status and health care use of Massachusetts women reporting partner abuse. Am J Prev Med 2000;19:302.

17. Lown EA, Vega WA. Intimate partner violence and health: Self-assessed health, chronic health, and somatic symptoms among Mexican American women. Psychosom Med 2001;63:352.

18. Wasson JH, Jette AM, Anderson J, Johnson DJ, Nelson EC, Kilo CM. Routine, single-item screening to identify abusive relationships in women. J Fam Pract 2000;49:1017.

19. Monahan K, O'Leary KD. Head injury and battered women: An initial inquiry. Health Soc Work 1999;24: 269.

20. Corrigan JD, Wolfe M, Mysiw WJ, Jackson RD, Bogner J. Early identification of mild traumatic brain injury in female victims of domestic violence. Am J Obstet Gynecol 2003;188:S71.

21. Westbrook LE, Devinsky O, Geocadin R. Nonepileptic seizures after head injury. Epilepsia 1998;39:978.

22. Fanslow JL, Norton RN, Spinola CG. Indicators of assault-related injuries among women presenting to the emergency department. Ann Emerg Med 1998;32:341.

23. Jackson HE, Philp E, Nuttall RL, Diller L. Traumatic brain injury: A hidden consequence for battered women. Prof Psychol Res Pract 2002;33:39.

24. Wilbur L, Higley M, Hatfield J, et al. Survey results of women who have been strangled while in an abusive relationship. J Emerg Med 2001;21:297.

25. Funk M, Schuppel J. Strangulation injuries. Wisconsin Medical Journal 2003;102:41.

26. Smith DJJ, Mills T, Taliaferro EH. Frequency and relationship of reported symptomology in victims of intimate partner violence: The effect of multiple strangulation attacks. J Emerg Med 2001;21:323.

27. Malek AM, Higashida RT, Halbach VV, et al. Patient presentation, angiographic features, and treatment of strangulation-induced bilateral dissection of the cervical internal carotid artery. Report of three cases. J Neurosurg 2000;92:481.
28. Purvin V. Unilateral headache and ptosis in a 30-yearold woman. Surv Ophthalmol 1997;42:163.

29. Young ME, Nosek MA, Howland C, Chanpong G, Rintala DH. Prevalence of abuse of women with physical disabilities. Arch Phys Med Rehabil 1997;78:S34.

30. Weinbaum Z, Stratton TL, Chavez G, MotylewskiLink C, Barrera N, Courtney JG. Female victims of intimate partner physical domestic violence (IPP-DV), California 1998. Am J Prev Med 2001;21:313.

31. Campbell J, Jones AS, Dienemann J, et al. Intimate partner violence and physical health consequences. Arch Intern Med 2002;162:1157.

32. McCauley J, Kern DE, Kolodner K, et al. The "battering syndrome": Prevalence and clinical characteristics of domestic violence in primary care internal medicine practices. Ann Intern Med 1995;123:774.

33. Zachary MJ, Mulvihill MN, Burton WB, Goldfrank LR. Domestic abuse in the emergency department: Can a risk profile be defined? Acad Emerg Med 2001; 8:796.

34. Leserman J, Li Z, Drossman D, Hu YJ. Selected symptoms associated with sexual and physical abuse history among female patients with gastrointestinal disorders: The impact on subsequent health care visits. Psychosom Med 1998;28:417.

35. Alexander RW, Bradley LA, Alarcon GS, et al. Sexual and physical abuse in women with fibromyalgia: Association with outpatient health care utilization and pain medication usage. Arthritis Care Res 1998;11:102.

36. Drossman DA, Leserman J, Nachman G, et al. Sexual and physical abuse in women with functional or organic gastrointestinal disorders. Ann Intern Med 1990;113:828.

37. Green CR, Flowe-Valencia H, Rosenblum L, Tait A. The role of childhood and adulthood abuse among women presenting for chronic pain management. Clin J Pain 2001;17:359.

38. Campbell LC, Riley JL, Kashikar-Zuck S, Gremillion $\mathrm{H}$, Robinson M. Somatic, affective, and pain characteristics of chronic TMD patients with sexual versus physical abuse histories. J Orofacial Pain 2000; 14:112.

39. Coker AL, Davis KE, Arias IA, et al. Physical and mental health effects of intimate partner violence for men and women. Am J Prev Med 2002;23:260.

40. Lown EA, Vega WA. Prevalence and predictors of physical partner abuse among Mexican American women. Am J Public Health 2001;91:441.

41. Coker AL, Pope BO, Smith PH, Sanderson M, Hussey JR. Assessment of clinical partner violence screening tools. J Am Med Wom Assoc 2001;56:19.

42. McFarlane J, Parker B, Soeken K, Bullock L. Assessing for abuse during pregnancy. Severity and frequency of injuries and associated entry into prenatal care. JAMA 1992;267:3176.

43. Hudson W. Partner abuse scale: Physical. Tempe, AZ: Walmyr Publishing Co., 1992.

44. Smith PH, Tessaro I, Earp JA. Women's experience with battering: A conceptualization from qualitative research. Womens Health Issues 1995;5:173. 
45. Smith PH, Smith JB, Earp JA. Beyond the measurement trap: A reconstructed conceptualization and measurement of woman battering. Psychol Wom Q 1999;23:177.

46. Attala JM, Hudson WW, McSweeney M. A partial validation of two short-form Partner Abuse Scales. Women \& Health. 1994;21:125.

47. Smith PH, Earp JA, DeVellis R. Measuring battering: Development and validation of the women's experience with battering (WEB) scale. Womens Health 1995;1:273.

48. Bureau of the Census. National health interview survey field representative's manual. Washington, DC: U.S. Public Health Service, HIS-100, 1994.
49. Coker AL, Reeder CE, Fadden MK, Smith PH. Physical partner violence and Medicaid utilization and expenditures. Public Health Rep 2004;119:557.

Address reprint requests to: Ann L. Coker, Ph.D. University of Texas, School of Public Health 1200 Herman Pressler P.O. Box 20186 Houston TX 77225

E-mail: Ann.L.Coker@UTH.TMC.EDU 
Copyright of Journal of Women's Health is the property of Mary Ann Liebert, Inc.. The copyright in an individual article may be maintained by the author in certain cases. Content may not be copied or emailed to multiple sites or posted to a listserv without the copyright holder's express written permission. However, users may print, download, or email articles for individual use. 